MATERIAєY

\title{
Agresja niemiecka i początki okupacji Polski w relacjach belgijskich obserwatorów
}

W trakcie prac nad realizacją projektu dotyczącego stosunków polsko-belgijskich $\mathrm{w} X X \mathrm{X}^{1}$. natrafiłem na ciekawe dokumenty stanowiące uzupełnienie materiałów opublikowanych w „Dziejach Najnowszych” przez Magdalenę Hułas $^{2}$, jak też interesującego artykułu z cennego numeru tego czasopisma poświęconego 70. rocznicy wybuchu II wojny światowej, autorstwa Kima Christiaensa i Idesbalda Goddeerisa ${ }^{3}$.

Agresja niemiecka na Polskę we wrześniu 1939 r. obrosła obfitą literatura, ale wiele zagadnień związanych z jej przebiegiem i stosunkiem opinii światowej do agresora pozostaje nadal mało znanych. Do takich należy m.in. kwestia odniesienia do naruszania prawa międzynarodowego w czasie kampanii ${ }^{4}$, jak też po klęsce Polski, zważywszy, że od czasu ostatniej wojny uległo ono znacznemu wzbogaceniu. Przełomowym wydarzeniem, jak się wydawało, było wprowadzenie zakazu wojny napastniczej w podpisanym przez większość istniejących państw pakcie Brianda-Kellogga z 1928 r. i jego korelacji z zasadami wypracowanymi przez Ligę Narodów. Podważał on występujący

${ }^{1}$ Dokumenty belgijskie dotyczace spraw polskich w czasie II wojny światowej są przygotowywane do wydania w ramach grantu finansowanego przez NCN nr 2018/30/M/H33/00153.

${ }^{2}$ M. Hułas, Kontakty dyplomatyczne Polski z Belgiq i Holandiq $w$ przełomowych momentach 1939 i 1940 r. Dokumenty, „Dzieje Najnowsze” 2010, nr 1, s. 152-166.

${ }^{3}$ K. Christiaens, I. Goddeeris, Polski Wrzesień w belgijskiej historiografii, „Dzieje Najnowsze” 2009, nr 3, s. 219-227.

${ }^{4}$ Zob. m.in.: J. Combacau, L'Etat en droit international, w: J. Combacau, S. Sur, Droit international public, Paris 1999, s. 291-295; Cz. Madajczyk, Faszyzm i okupacje 1938-1945, t. I-II, Poznań 1983-1984; H. Batowski, Polska dyplomacja na obczyźnie 1939-1941, Kraków 1991, s. 44-54; idem, Walka dyplomacji hitlerowskiej przeciw Polsce 1939-1945, Kraków-Wrocław 1984; J. Sobczak, Polska w propagandzie i polityce III Rzeszy w latach 1939-1945, Poznań 1988, s. 89 i n., 152.

${ }_{5}^{5}$ Zob. J. Łaptos, Pakt Brianda-Kellogga. Stanowisko państw europejskich wobec zagadnienia rezygnacji z wojny napastniczej $w$ stosunkach międzynarodowych, Kraków 1988. 
dotychczas $\mathrm{w}$ powszechnym prawie narodów sposób dokonywania zmian terytorialnych nie tylko przez traktat pokojowy, ale także przez debellatio, „zawojowanie”, czyli w wyniku jednostronnej decyzji zwycięzcy w wojnie. Prawo międzynarodowe nie znało też do tego czasu pojęcia zbrodni agresji jako czynu, który można byłoby przypisać konkretnym sprawcom w celu pociagnięcia ich do międzynarodowej odpowiedzialności karnej ${ }^{6}$. Miało to decydujący wpływ na pojmowanie ciagłości państwowości w czasie okupacji. Precedens w tej kwestii stanowiła sprawa Belgii podczas I wojny światowej. W wyniku agresji niemieckiej i naruszenia statusu tzw. wiecznej neutralności Belgii przez jednego z jej gwarantów rząd tego państwa schronił się na terytorium Francji, która uznała, że wobec zaistniałych faktów może on być uznany za kontynuatora państwowości i korzystać ze wszystkich uprawnień przysługujacych rządom państw suwerennych w czasie pokoju, w tym posiadania swych przedstawicieli dyplomatycznych w krajach neutralnych i należących do koalicji antyniemieckiej. To bezprecedensowe rozwiazanie zostało wprowadzone de facto do prawa międzynarodowego i stanowić miało oparcie dla wszystkich państw będących ofiarami niesprowokowanej agresji oraz wynikającej z niej nielegalnej okupacji, tym bardziej że w tym kierunku szły zobowiązania wynikajace ze wspomnianego paktu Brianda-Kellogga, a także tzw. doktryny Stimsona ${ }^{7}$. Uznanie, że rządy działające na emigracji stanowią o prawnej kontynuacji państwowości, stwarzało dla krajów okupowanych w czasie II wojny światowej szansę posiadania własnych przedstawicieli dyplomatycznych w innych krajach, zaciagania pożyczek, współpracy $\mathrm{w}$ walce przeciwko wspólnemu wrogowi, organizowania własnych sił zbrojnych itp.

Belgia, podobnie jak wiele mniejszych krajów europejskich, stojąc przed perspektywą wojny, wybrała politykę neutralności, z którą wiązała pewne korzyści, ale też zobowiązania. Należąc do grupy Oslo ${ }^{8}$, była moralnie zobowiązana postępować zgodnie z pozostałymi członkami tej grupy, a przy tym miała powody, wskazane wyżej, powoływania się na swe doświadczenia z okresu długotrwałej neutralności, jak i jej pogwałcenia w 1914 r. Jak dalece te doświadczenia rzutowały na reakcję państw grupy Oslo (a także

${ }^{6}$ G. Gaja, The Long Journey Towards Repressing Aggression, w: The Rome Statute of the International Criminal Court, red. A. Cassese, P. Gaeta, J.R.W.D. Jones, Oxford 2002, s. 427-441.

${ }^{7}$ Sformułowana w styczniu 1932 r. przez sekretarza stanu USA Henry’ego Stimsona doktryna ta została potwierdzona w marcu tegoż roku przez Ligę Narodów. To ważne osiagnięcie dyplomacji amerykańskiej, która w argumentach natury moralnej szukała sposobów rozwiązywania sytuacji konfliktowych. 23 VII 1940 Sumner Welles ogłosił deklarację nieuznania zajęcia krajów bałtyckich.

${ }^{8}$ Państwa, które wybierając status neutralności, podpisały w 1930 r. porozumienie mające na celu prowadzenie konsultacji dotyczących problemów regionu oraz zobowiązań wynikających z neutralności. Należały do niej: Belgia, Dania, Finlandia, Holandia, Luksemburg, Norwegia i Szwecja. 
na stanowisko wielu innych członków wspólnoty międzynarodowej), dowodzi zacytowany przez polskiego posła w Hadze - Wacława Babińskiego ${ }^{9}$ - fragment decyzji holenderskiego Ministerstwa Spraw Zagranicznych (MSZ): „,...] neutralność nasza wymaga, by Holandia uznawała nadal Rząd Polski, jak to uczyniła w poprzedniej wojnie światowej w stosunku do rządu belgijskiego, którego siedziba przeniesiona była także za granicę"10.

Publikowane poniżej dokumenty potwierdzają zasady moralne, jakimi kierowała się dyplomacja belgijska w 1939 r. wobec rządu polskiego działającego na emigracji najpierw w Paryżu, a potem w Angers, jak też w okresie, gdy rządy obu krajów znalazły się na uchodźstwie w Londynie po klęsce Belgii w $1940 \mathrm{r}$.

Postawa Belgii, ofiary agresji niemieckiej w czasie I wojny światowej, w stosunku do Polski, która znalazła się w analogicznej sytuacji, nacechowana była nie tylko zrozumiała skądinąd empatia, ale też wynikała z faktu, że Belgia była przed wojna trzecim po Francji i Stanach Zjednoczonych inwestorem w Polsce. Losy jej przedsiębiorstw, zarówno pod okupacja, jak i po odzyskaniu niepodległości przez Polskę, nie mogły być obojętne ani politykom, ani bezpośrednio zainteresowanym przedsiębiorcom, co podkreśla poseł Alexandre Paternotte de la Vaillée ${ }^{11}$ w raporcie z 11 października (dok. 13), precyzując, że obywatele jego kraju zainwestowali nad Wisła półtora miliarda franków belgijskich. Załączone tu raporty wskazują wyraźnie na wagę tego problemu, ale tė̇ na ostrożne stanowisko wobec okupanta niemieckiego w okresie poprzedzającym atak niemiecki na Belgię ${ }^{12}$ (dok. 9 i 13).

Uderza także wrażliwość na przestrzeganie humanitarnych zasad w prowadzeniu wojny. Już 3 września ambasador Patternotte wskazuje na potrzebę ostrzeżenia rządu polskiego przed zbyt pochopnym oskarżaniem Niemców o bombardowanie ludności cywilnej, przypominając, że za pośrednictwem rządu holenderskiego obie strony zobowiązały się do unikania bombardowania ludności cywilnej. Radzi czekać na potwierdzenie takich przypadków przez wiarygodna instytucję, jak np. Międzynarodowy Komitet Czerwonego Krzyża czy Zakon Maltański. Stanowisko to podtrzymuje jeszcze 12 września, mimo coraz częstszych świadectw, w obawie, że użytek, jaki rząd polski czyni z tych faktów, może spowodować represje ze strony Niemiec.

${ }^{9}$ Wacław Babiński (1887-1957), dyplomata polski; poseł RP w Belgradzie (1929-1931); przy rządzie holenderskim w Hadze, a następnie w Londynie (1931-1944); szef misji polskiej w Ottawie (1944-1945).

${ }_{10}$ M. Hułas, op. cit., s. 154, dok. 4, 25 X 1939, W. Babiński do A. Zaleskiego.

11 Alexandre Paternotte de la Vaillée (1888-1973), dyplomata belgijski. Od 1936 r. do kwietnia 1940 minister pełnomocny Królestwa Belgii w Warszawie, a następnie w Angers przy rządzie polskim na emigracji. W latach 1948-1953 ambasador Belgii w Watykanie.

12 To stanowisko nadmiernie akcentuja autorzy wspomnianego artykułu, wysuwając dyskusyjną tezę, że uznanie rządu polskiego w Paryżu mogłoby zagrozić neutralności Belgii. K. Christiaens, I. Goddeeris, op. cit., s. 220. 
Jednakże dzień później przebywając wraz z rządem polskim w Krzemieńcu, zostaje świadkiem celowych nalotów, dokonanych po odjeździe przedstawiciela sowieckiego i konsula niemieckiego, na dzielnice miasteczka zamieszkałe przez ludność cywilną (dok. 10) i gotów jest poprzeć inicjatywę nuncjusza papieskiego o zwrócenie się do papieża z prośbą o podjęcie akcji humanitarnej dla cywilnych ofiar nalotów.

Sytuacja Belgii jako państwa neutralnego pozwalała na posiadanie na terytorium Polski niektórych przedstawicieli, głównie związanych z przemysłem, oraz konsula honorowego, co dawało MSZ możliwość orientowania się w polityce okupanta i w sytuacji ludności polskiej (dok. 14 i 17).

Raporty, które publikuję poniżej, dowodzą owego szczególnego zainteresowania Polską i odsłaniają niektóre strony okupacji, a przy tym są cennymi relacjami naocznych świadków, wzbogacającymi naszą wiedzę o tych tragicznych wydarzeniach.

Publikowane dokumenty pochodzą z archiwum belgijskiego Ministerstwa Spraw Zagranicznych i Handlu Zewnętrznego. Publikowane są w całości. Pominięte zostały tylko zapiski o charakterze kancelaryjnym, służące klasyfikacji dokumentów w odpowiednich działach MSZ. Skorygowano pisownię, w tym błędy literowe, ortograficzne i interpunkcyjne, nie poprawiano natomiast stylu i składni. Oryginalne podpisy zaznaczono kursywa. Podpisy w pozostałych dokumentach dowodza, że mamy do czynienia z odpisami (kopiami).

Józef Łaptos

Kraków

\section{1}

Ministère des Affaires Etrangères et du Commerce Extérieur

Cabinet, télégramme chiffré secret, $\mathrm{n}^{\circ} 151^{13}$.

Varsovie, le 1 septembre 1939, $14.40 \mathrm{~h}$.

D'après déclaration qui m'a été faite ce matin, je crois en conclure que [le] gouvernement polonais se considère comme en état de guerre de facto [avec] $\underline{\text { l'Allemagne }}^{14}$. Ambassadeur polonais [à] Berlin ${ }^{15}$ a reçu l'ordre de demander

\footnotetext{
${ }^{13}$ Archives du Ministère des Affaires Etrangères et du Commerce Extérieur (dalej: AMAEB), t. 11 078, Série générale - Pologne.

${ }^{14}$ Podkreślone w tekście.

15 Józef Lipski (1894-1958), prawnik, dyplomata polski; od 1933 r. poseł, a następnie ambasador II RP w Berlinie; 26 I 1934 podpisał w imieniu rządu polskiego pakt o nieagresji z Konstantinem von Neurathem. W czasie wojny znalazł się w gronie współpracowników kolejnych wodzów naczelnych Armii Polskiej na Zachodzie.
} 
[les] passeports. Chargé d'affaires [de l'] Allemagne ${ }^{16}$ vient de demander ses passeports.

Paternotte

\section{2}

Ministère des Affaires Etrangères et du Commerce Extérieur Cabinet, télégramme chiffré secret $\mathrm{n}^{0} 155^{17}$.

Varsovie, le 3 septembre 1939, $17.20 \mathrm{~h}$.

Vous avez appris que les belligérants ont échangé, par l'intermédiaire du gouvernement des Pays Bas, l'assurance qu'ils ne bombarderaient pas les populations civiles, sous réserve de réciprocité.

Or, je constate une tendance, à mon avis très dangereuse, à accuser déjà l'adversaire de violer délibérément cet engagement. Je me permets suggérer, à titre personnel, que S. M. le Roi daigne examiner la possibilité de prendre, d'accord avec la Reine des Pays-Bas, l'initiative de faire les propositions suivantes aux gouvernements intéressés:

$1^{\circ}$ ceux-ci s'engageraient à ne pas reprendre leur liberté d'action sans une déclaration publique dans ce sens;

$2^{\circ}$ ils accepteraient la présence dans toutes les agglomérations, tant soit peu importantes, d'observateurs neutres, délégués par la Croix Rouge internationale, l'Ordre de Malte et autres associations charitables qui seraient chargées de constater si les bombardements, ayant fait des victimes civiles, étaient réelement dirigés contre celle-ci ou constitueraient des erreurs ou accidents toujours possibles ne pouvant être invoqués pour justifier des représailles.

Je suis, en effet, très porté à croire que les victimes civiles faites ici, ces derniers jours, n'ont pas été visées délibérément.

Je n'ai pas fait part de ma suggestion au Gouvernement polonais. Si vous croyez pouvoir donner suite à ma proposition, je vous engage à agir avec la plus grande urgence étant donné l'excitation croissante de l'opinion publique.

Paternotte

16 John von Wühlisch (1889-1943), dyplomata niemiecki; radca ambasady i chargé d'affaires III Rzeszy w Warszawie od 1933 r.; w latach 1939-1942 szef misji dyplomatycznej przy Generalnej Guberni. Szerzej zob. T. Rabant, Antypolska działalność niemieckiej stużby dyplomatycznej $i$ konsularnej $w$ Polsce $w$ przededniu II wojny światowej oraz jej ewakuacja i likwidacja, „Pamięć i Sprawiedliwość” 2006, nr 1 (9), s. 199-215, bazhum.muzhp.pl/.../ Pamiec_i_Sprawiedliwosc-r2006-t5-n1(9)-s199-215.pdf (dostęp: 14 XII 2019).

${ }_{17}$ AMAEB, t. 11 078. Na marginesie odręcznie: Le texte de ce télégramme ne peut être communiqué à des tiers qu'après avoir été préalablement paraphrasé. 
Ministère des Affaires Etrangères et du Commerce Extérieur Cabinet, télégramme chiffrée $\mathrm{n}^{0} 157^{18}$

Varsovie, le 4 septembre [19]39.

Votre [tel.]74 (8)*, Votre lettre du 27 août ne m'est parvenue, envoyez duplicatum par avion via Riga. Entre temps [je] vous suggère [de] faire [une] déclaration verbale dont vous télégraphieriez substance.

Paternotte

$\left.{ }^{*}{ }^{*}\right)$ à $\mathrm{P}[$ aternotte], le 2 septembre 1939. Déclaration [de] neutralité [de la] Belgique.

Ministère des Affaires Etrangères et du Commerce Extérieur Cabinet

Télégramme chiffrée secret $\mathrm{n}^{\circ} 161^{19}$

Varsovie, le 6 septembre 39, 20 h. 08.

Suite à mon télégramme $158^{20}$. Se conformant à [la] conduite de majorité de ses collègues, Ministre a quité ce matin Varsovie avec [le] second secrétaire pour essayer rejoindre le Guvernement polonais. Je reste [à] Varsovie avec les autres pour garder la Légation et assister colonie belge. J'ai gardé le code. Ministre a reçu votre [tel.]77. Il est en possession [du] texte [de la] déclaration [de] neutralité corrigé par votre [tel.] 74. Il fera communication le plus tôt possible. Gouvernement polonais, à 15 heures, a prié officiellement toutes les légations [d']évacuer dans [la] direction [de] Lublin. Se refuse assumer [la] responsabilité de la sécurité du corps diplomatique à Varsovie, en raison [des] bombardements aériens qui s'étendent [au] centre ville et aux ponts [du] fleuve. Mon collègue [de] Pays-Bas ${ }^{21}$, dépourvu [du] code, m'a prié de vous demander de communiquer cette dernière information à la Haye, en ajoutant que nombreux Hollandais sont réfugiés à sa Légation. Je suis, ainsi que mes collaborateurs, dans l'impossibilitié matérielle et morale de changer ${ }^{22}$. D'Aspremont-Lynden ${ }^{23}$

${ }^{18}$ Ibidem, Pologne - politique générale.

19 Ibidem.

${ }^{20}$ Nie znaleziono w zbiorach AMAEB.

${ }^{21}$ Johan B. Bosch Ridder van Rosenthal (1889-1955?), poseł Holandii w Warszawie, a następnie przy rządzie RP w Angers i w Londynie do 1945 r.

22 AMAEB, t. 11 078, Notatka na marginesie: «fait par Cabinet».

${ }^{23}$ Geoffroy, hr. d'Aspremont Lynden (1904-1979), dyplomata belgijski. W 1937 r. został sekretarzem Poselstwa w Warszawie. We wrześniu 1939 r. organizował ewakuację ok. 1400 
Ministère des Affaires Etrangères et du Commerce Extérieur Cabinet, télégramme chiffré secret $\mathrm{n}^{\circ} 4^{24}$

Krzemieniec, le 9 septembre 39, $18.15 \mathrm{~h}$.

Goering a déclaré aujourd'hui que la résistance [de la] Pologne sera terminée avant quatre semaines et [permettra] la libération de forces importantes pour [le] front ouest. Ceci me paraît très vraisemblable et [des] conséquences possibles pour notre pays doivent être prises en sérieuse considération.

Paternotte

\section{6}

Ministère des Affaires Etrangères et du Commerce Extérieur

Cabinet

Télégramme chiffré secret $\mathrm{n}^{\circ} 10^{25}$

Krzemieniec, le 12 septembre 1939, 13,50 h.

D'après [la] déclaration que m'a faite personnellement un ingénieur suisse digne de foi, l'aviation allemande s'est livrée ces derniers jours à de regrettables excès en bombardements sur plusieurs centres de population civile sans utilité militaire. L'ingénieur a été témoin de ces bombardements. Gouvernement polonais paraît vouloir exploiter au maximum ces incidents. Il a créé de ce fait une situation dangéreuse pouvant provoquer [les] représailles qui iront fatalement en s'élargissant. Puis-je vous demander s'il vous a été possible de donner suite [à la] suggestion contenue dans mon télégramme du 3 septem$b^{2} e^{26}$. Au moment où je vous télégraphie, un certain nombre des bombes sont lancées sur la ville qui de toute évidence ne présente aucun trafic militaire.

Paternotte

\section{7}

Ministère des Affaires Etrangères et du Commerce Extérieur

Cabinet, télégramme chiffré $\mathrm{n}^{\circ} 163^{27}$ du 13 septembre 1939.

dyplomatów z Warszawy. Współpracował ściśle z polskim rządem na emigracji w Londynie w okresie wojny. W latach 1944-1945 był radca ambasady belgijskiej w Paryżu.

${ }^{24}$ AMAEB, t. 11078.

${ }^{25}$ Ibidem.

${ }^{26}$ Zob. dok. 2.

${ }^{27}$ AMAEB, t. 11 078. Dopisano ołówkiem: Lysak, Jakubowska Paulina. 
Prière [de] faire annoncer par radio que personnel [en] poste ainsi que [les] Belges et Luxembourgeois suivants, refugiés avec [leur] famille à la Légation ou en contact avec elle vont bien: Tancret, Gabszewicz, Adrianssens, Steinhaus, Masquelier, Vandesande, Toussain Rolling, Huart, Bruyneel, Elza Dehagen fils, Chapuis, Felde, Bonem Jeanne, Regout, Mathieu Porten Van Ginderdeuren, Speder Mariette, Pirson Halber.

Prière [d']aviser vingt-et un, [rue] Labruyère [à] Paris, la famille Leszniak, que famille Duverger va bien. Nombre [des] réfugiés [à la] Légation atteint quarante. Prière [d']accuser [la] réception, si possible.

D'Aspremont-Lynden

Télégramme [en clair n $\left.{ }^{\circ} 11\right] 1389^{28}$.

Krzemieniec, le 12 septembre 1939.

Suite [de] $\mathrm{n}^{\circ} 10$. [du 12 septembre 1939]

Plusieurs avions ont lancé ce matin sous nos yeux [une] douzaine de bombes sur la ville. Stop. Il n'y a ici aucun garnison ni établissement militaire quelconque. Une vingtaine [de] missions diplomatiques y ont établi siège. Stop. Avons constaté de visu victimes civiles et nombreuses maisons détruites. On chiffre seize morts et une quarantaine de blessés.

Paternotte.

\section{9}

Légation de Belgique Krzemieniec, le 13 septembre 1939

Rapport $\mathrm{n}^{\circ} 1^{29}$.

A. Paternotte de la Vaillée, ministre de Belgique en Pologne, à Spaak, Ministre des Affaires Etrangères et du Commerce Extérieur.

J'ai l'honneur de confirmer mes télégrammes nº 10 et 11 du 12 septembre et $\mathrm{n}^{\circ} 12 \mathrm{du} 13$ septembre.

Le bombardement aérien dont je vous donnais la nouvelle s'est produit vers $10 \mathrm{~h}$. 30.- Il a été effectué par une escadrille, volant très bas, ce qui prouve qu'il ne s'agit pas de l'acte inconsidéré d'un aviateur isolé ayant perdu la notion des ses responsabilités, et ce qui prouve aussi que les assaillants savaient n'avoir à redouter aucune D.T.C.A. ${ }^{30}$.

${ }^{28}$ Ibidem.

${ }^{29}$ Rękopis. Odręcznie na marginesie: «Vu à la comptabilité. Le 500 zlotys ont été porté au compte par M. Peternotte».

${ }^{30}$ Défense Terrestre Contre Aéronefs. 
Plusieurs bombes sont tombées à proximité de la maison ou j'habite avec M. Hupperts ${ }^{31}$. Des graviers et au--tres matières ont été envoyés jusque dans les jardins attenant au notre. Nous avons pu suivre de visu, la chute des bombes et leur éclatement.

Après le raid, je me suis rendu avec plusieurs collègues dans les quartiers sinistrés. J'ai eu constaté que de nombreuses maisons étaient en flammes et éventrées dans les rues principales de la ville. J'ai vu des cadavres des victimes. Mon collègue des Pays-Bas en a compté 16 . Le chiffre total est, me dit-on, de 30 outre 40 blessés.

D'après ce que j'ai pu voir, les aviateurs ont traversé la localité de part en part, suivant plus ou moins les quartiers populeux qu'ils pouvaient reconnaître facilement étant donné la faible hauteur de leur vol, en y jetant leurs bombes. Une douzaine de projectiles ont été lancés, deux ou trois de ceux-ci n'ont pas éclaté. Les éclats que j'ai vus, avaient environ 1 centimètre et $1 / 2$ centimètre d'épaisseur.

Il n'y a aucun doute que le raid a été dirigé délibérement contre la population civile. A ma connaissance il n'y a à Krzemeniec aucun établissement militaire $^{32}$. Les seuls soldats que j'y ai rencontrés étaient des isolés qui semblaient être plutôt des fonctionnaires et de la police d'Etat, cmme il y a en a dans toutes les villes de la Pologne même en temps de paix.

Etant donné que le Ministère des Affaires Etrangères se trouve établi dans cette ville, je ne sais si l'on peut dire que celle-ci constitue un objectif militaire pouvant être bombardé sans qu'il y ait violation des usages de la guerre. Ce qui est indiscutable cependant, c'est que les aviateurs se sont attaqués aux quartiers très habités, aisément reconnaissables. Ce qui est également un fait établi, c'est que le raid a eu lieu quelques heures après le départ d'un Consul d'Allemagne encore déténu ici et envoyé le matin même à la frontière, et après le départ de l'Ambassadeur des Soviétiques ${ }^{33}$ qui avait quitté la ville pour son pays ${ }^{34}$ emmenant les dames de la mission.

Dans un télégramme d'hier, je vous disais que je considérais que nous sommes ici en danger sérieux. Je ne puis que confirmer cette opinion aujourd'hui. Il n'y a [pas] à Krzemieniec pour le moment, ni abri, ni D.T.C.A. Les avions allemands ont le champ libre et peuvent détruire toute la ville en quelques minutes s'ils le veulent.

\footnotetext{
${ }^{31}$ Albert Hupperts (1911-1974), dyplomata belgijski; wicekonsul w Warszawie w latach trzydziestych XX w. W 1956 r. brał udział w negocjacjach i redagowaniu traktatów rzymskich.

${ }^{32}$ Podkreślone ołówkiem.

${ }_{33}$ Nikołaj Iwanowicz Szaronow (ros. Николай Иванович Шаронов; ur. 1901-?), dyplomata sowiecki; ambasador ZSRR w Warszawie od 2 VI 1939; wyjechał z Krzemieńca 10 września pod pretekstem szukania po drugiej stronie granicy bezpośredniego połączenia telefonicznego ze swym ministerstwem. Następnie był ambasadorem w Budapeszcie do 23 VI $1941 \mathrm{r}$. Dalszych jego losów nie znamy.

${ }^{34}$ Podkreślone ołówkiem.
} 
Quelques membres du Corps Diplomatique, étant les chefs de mission à l'exception de 6 sont ici-, [Ils] sont dans un état voisinant la panique. Certains ont déjà quitté la ville. D'autres brûlent du désir de s'en aller. Il va de soi que si les réprésentants de pays se trouvant dans la sitaution similaire à la nôtre prennent une initiative dans ce sens. Je fais allusion notamment aux ministres des Pays-Bas, Suède, Suisse, Espagne, Hongrie, Baltes etc.

Hier après midi, le nonce ${ }^{35}$ nous a réunit et nous a proposé d'envoyer un télégramme collectif au Saint-Père ${ }^{36}$, dans lequel, après avoir relaté les faits dont nous avons été témoins, nous eussions émis le voeu qu'une initiative du caractère humanitaire fût prise. Cette proposition a été rejetée par $\underline{\text { l'Ambassadeur d'Italie }}^{37}$ et le Ministre d'Espagne ${ }^{38}$. Le premier s'est refusé à signer un document pouvant être interprété comme un jugement sur les événements dont nous avons été témoins. Le Ministre de Bulgarie ${ }^{39}$ a adopté une attitude plus au moins analogue. Comme l'unanimité ne pouvait pas se faire parmi les chefs de mission, l'initiative dont il s'agit a été abandonnée et un procès-verbal de la réunion à été dressé.

J'ajoute quil a été convenu entre de nombreux collègues que nous enverrions chacun 500 zlotys au bourgemestre de la ville de Krzemieniec en vu de soulager les victimes du désastre. J'espère que vous approuverez cette mesure.

Paternotte de la Vaillée

Ministère de l'Intérieur APPEL A L'ACTION

Le 18 septembre 1939

(reçu du Ministère de l'Intérieur, communiqué aux Aff[aires] Ext[érieures] par le major Bruyère $\left.{ }^{40}\right)$.

${ }^{35}$ Filippo Cortesi (1876-1947), włoski duchowny katolicki, dyplomata watykański. W latach 1926-1936 był nuncjuszem apostolskim w Argentynie. W latach 1936-1939 - nuncjuszem apostolskim w Polsce i pełnił zarazem funkcję dziekana korpusu dyplomatycznego.

${ }^{36}$ Pius XII, właśc. Eugenio Maria Giuseppe Giovanni Pacelli (1876-1958). W latach 1930-1939 sekretarz stanu Stolicy Apostolskiej. Papież i suweren Państwa Watykańskiego od 2 III 1939 do 9 X 1958.

37 Pietro Arone di Valentino, ambasador Królestwa Włoch w Polsce od 1936 r.

${ }^{38}$ Luis de Pedroso y Madan, hr. San Estaban de Cañongo (1876-1952), ambasador Hiszpanii w Warszawie od czerwca $1939 \mathrm{r}$.

${ }^{39}$ Pietr Trajanow, dyplomata bułgarski, chargé d'affaires Poselstwa w Warszawie od czerwca $1936 \mathrm{r}$.

${ }^{40}$ Communiqué aux Aff[aires] Ext[érieures] par le major Bruyère. 
Maintenant, que la Pologne a été dévastée et détruite, toutes les nations européennes peuvent clairement se rendre compte quel sort les attends de la part d'une Allemagne victorieuse.

Ces diverses nations, Pays scandinaves, Hollande, Belgique, Suisse, Yougoslavie, Roumanie, Hongrie etc. «continueront-elles leur politique d'autruche avec la perspective certaine d'être étranglés un jour, l'une après l'autre». Ou bien prendront - de commun accord, et avant qu'il soit trop tard, la seule décision possible, c'est-à-dire un appel immédiat à la Grande Bretagne et à la France «de venir protéger leurs territoires contre la menace d'envahissement par l'Allemagne?»

Le salut et la vie de toutes ces nations dépend indubitablement d'une action immédiate de leur part.

\section{1}

Légation de Belgique Bucarest, le 21 septembre 1939.

Rapport $\mathrm{n}^{\circ} 2^{41}$

Paternotte de la Vaillée, ministre de Belgique en Pologne, à Monsieur P.-H. Spaak, ministre des Affaires Etrangères et du Commerce Extérieur

Comme suite à mon télégramme $\mathrm{N}^{\circ} 15^{42}$ du 19 de ce mois, j'ai l'honneur de vous faire savoir que le Président de la République de Pologne a fait tenir aux chefs de missions réunis à Cernauti, avant leur départ pour Bucarest, le message suivant:

"Nous considérons que tout le Corps Diplomatique, qui était accrédité auprès du Président Moscicki et du Gouvernement actuel, se trouve accrédité - sauf avis contraire des Gouvernements intéressés - auprès du nouveau gouvernement polonais qui s'établira en France dans une ville où il jouira de l'exterritorialité».

«En attendant que le Gouvernement soit établi dans sa nouvelle résidence, les communications lui seront transmises par l'intermédiare des Ambassades et Légations de Pologne à l'étranger».

A. Paternotte de la Vaillée

Légation de Belgique Bucarest, le 22 septembre 1939.

Rapport $n^{\circ} 3$

${ }^{41}$ AMAEB, t. 11 078, Oryginał.

${ }^{42}$ Brak w zbiorach AMAEB. 
A. Paternotte de la Vaillée, ministre de Belgique en Pologne, à Monsieur P.-H. Spaak, ministre des Affaires Etrangères et du Commerce Extérieur

\section{Objet: Départ de Cernauti ${ }^{43}$}

Comme suite à ma lettre du 21 de ce mois $\mathrm{n}^{\circ} 2$, j'ai l'honneur de vous communiquer, ci-dessous, des précisions sur les circonstances dans lesquelles a été fait le message du chef du Gouvernement Polonais au Corps Diplomatique, en résidence à Cernauti ${ }^{44}$, le 18 Septembre dernier.

A Cernauti, le 18 Septembre, le Chef du protocole exposa au Corps Diplomatique, au nom du Ministre Beck qu'il avait voulu convoquer à des audiences privées, à la Résidence Royale roumaine, tous les chefs de missions accrédités, mais que le Ministre des Affaires Etrangères roumain l'avait prié de s'abstenir de toute réception susceptible d'être interpretée comme un acte politique.

M. Beck suggera alors qu'il ferait visite aux Chefs de Mission dans leurs hôtels respectifs, mais le Gouvernement roumain s'y opposa également.

Le Président et le Gouvernement polonais durent, malgré eux, abandonner le territoire polonais et traverser la frontière roumaine en raison des attaques militaires convergeantes allemandes et russes, qui leur coupèrent toute retraite. M. Moscicki et le Gouvernement polonais se considérent toujours en fonction et ne séjournent que temporairement en Roumanie. Ils ont l'intention de se rendre en France dans une ville à choisir et qui aurait l'extérritorialité, pour contunuer l'activité gouvernementale qui, selon le droit constitutionnel polonais, serait entièrement légale.

Au nom du président de la République M. Beck déclara textuellement:

«Nous considérons que tout le Corps Diplomatique, qui était accrédité auprès du Président Mościcki et auprès de son Gouvernement, continuera automatiquement à être accrédité auprès du Gouvernement à transférer dans une ville française. Jusqu'au moment où le Gouvernement sera établi dans une nouvelle résidence en France, les relations avec lui seront effectuées par l'intermédiaire des Missions diplomatiques polonaises à l'étranger».

A. Peternotte de la Vaillée

${ }^{43}$ Cernăuți (Czerniowce), miasto w północnej Bukowinie nad Prutem; w latach 1919-1940 należało do Rumunii.

${ }^{44}$ Szczegóły zob. T. Wyrwa, Ambasador Francji w Bukareszcie o sytuacji rzadu polskiego we wrześniu 1939 r., „Zeszyty Historyczne” (Paryż) 1987, z. 28, s. 186-190. 
Note du Ministère des Affaires Etrangères et du Commerce Extérieur sur la question du maintien d'une mission diplomatique belge auprès du nouveau Gouvernement polonais ${ }^{45}$.

A)

Faits:

Les territoires qui formaient la République de Pologne ont été partagés entre l'Allemagne et l'Union des Républiques socialistes soviétiques.

D'autre part, le Président de la République de Pologne, M. Ignace Moscicki ${ }^{46}$, et le Gouvernement polonais ayant été internés en Roumanie, un nouveau président a été désigné et un nouveau Gouvernement constitué, le 30 septembre dernier.

Ce nouveau Gouvernement polonais est ainsi constitué:

1) Président du Conseil et Ministre des Affaires Etrangères: général Wladislaw Sikorski ${ }^{47}$

2) Vice-Président du Conseil: M. Stanislas Stronski ${ }^{48}$;

3) Ministre des Affaires Etrangères: M. August Zaleski ${ }^{49}$;

4) Ministre de Finances: M. Adam Koc ${ }^{50}$;

5) Ministre de la Prévoyance Sociale: M. Stanczyk ${ }^{51}$;

${ }^{45}$ AMAEB, t. 11 078, Dopisek na marginesie: «Direction Générale de la Politique».

${ }^{46}$ Michał Mościcki (1894-1961), w służbie dyplomatycznej od 1920 r. W latach 1921-1924 pracował w Poselstwie w Tokio, w latach 1924-1928 w Paryżu; w latach 1933-1936 poseł w Tokio. Od 25 X 1937 do grudnia 1939 był posłem RP w Belgii i Luksemburgu.

${ }^{47}$ Władysław Sikorski (1881-1943), polski polityk i wojskowy. 20 IX 1939 r. został premierem rządu na uchodźstwie, uznanego przez Anglię i Francję, a następnie przez sojuszników i inne państwa. Siedzibą rządu był początkowo Paryż, potem Angers, a po klęsce Francji Londyn. 7 XI 1939 r. został Naczelnym Wodzem. Zginął w katastrofie lotniczej 4 VII 1943 r.

${ }^{48}$ Stanisław Stroński (1882-1955 w Londynie), polski filolog romanista, publicysta i polityk związany z ruchem narodowym. W latach 1939-1943 w rządzie emigracyjnym Sikorskiego wicepremier i minister informacji i dokumentacji.

${ }^{49}$ August Zaleski (1883-1972), polityk i dyplomata polski. W latach 1926-1932 i ponownie 1939-1941 minister spraw zagranicznych; w latach 1947-1972 prezydent rządu polskiego na emigracji.

${ }^{50}$ Adam Ignacy Koc (1891-1969), polityk, poseł, dziennikarz, pułkownik dyplomowany piechoty Wojska Polskiego. 30 IX 1939 został powołany na stanowisko ministra skarbu w rządzie Sikorskiego, a 9 października przyją także tekę ministra przemysłu i handlu. Był jednym z dwóch piłsudczyków wchodzących w skład rządu emigracyjnego. 9 XII 1939 r. podał się dymisji.

51 Jan Stańczyk (1886-1953), działacz socjalistyczny i związkowy. We wrześniu 1939 opuścił Polskę i dotarł do Paryża. Od 2 X 1939 do 24 XI 1944 był ministrem pracy i opieki społecznej w rządach: Sikorskiego i Stanisława Mikołajczyka. Po rozmowach z rządem 
6) Ministres sans portefeuille: Général Josef Haller ${ }^{52}$ et M. Alexandre Lados $^{53}$.

M. Wladyslaw Raczkiewicz ${ }^{54}$ avait été, conformément à la loi constitutionnelle de la République de Pologne du 23 avril 1935, désigné comme successeur éventuel par ordonance du Président de la République du 17 septembre 1939, signé à Kuty (Pologne) et promulguée dans le «Monitor Polski», n 214 à 27, paru à Paris le 29 septembre 1939.

Le gouvernement belge a été informé de cette désignation par une lettre de la Légation de Pologne à Bruxelles en date du $1^{\text {er }}$ octobre 1939, à laquelle il a été répondu, le 9 octobre, par un simple accusé de réception.

\section{B)}

Problèmes qui se posent pour la Belgique:

$1^{\circ}$ la reconnaissance par sa Majesté le Roi des Belges du nouveau Président de la République de Pologne;

$2^{\circ}$ l'envoi auprès du nouveau Gouvernement polonais du chef de notre mission diplomatique qui était accrédité auprès du Gouvernement de Varsovie.

\section{$1^{\circ}$}

D'après les renseignements que possède le Département, ont officiellement reconnu le nouveau président de la République de Pologne:
A. les Etats-Unis d'Amérique,
B. la France,
C. la Grande Bretagne et
D. le Mexique,

lubelskim powrócił do kraju i pełnił funkcję ministra pracy i opieki społecznej w rządzie Edwarda Osóbki-Morawskiego.

52 Józef Haller von Hallenburg (1873-1960), wojskowy i polityk, generał broni WP. Jeden z głównych organizatorów i dowódców Legionów Polskich. Po przedostaniu się do Francji przyją zadanie tworzenia armii polskiej z ramienia Komitetu Narodowego Polskiego. Do niepodległej Polski wrócił w 1919 r. wraz ze swą Błękitną Armią i brał udział w wojnie polsko-bolszewickiej. Odsunięty od polityki po przewrocie majowym. W 1939 r. na emigracji znalazł się w rządzie Sikorskiego jako minister bez teki. W latach 1940-1943 pełnił funkcję ministra oświaty w rządzie polskim na uchodźstwie.

53 Aleksander Wacław Ładoś (1891-1963), polski dyplomata, publicysta i polityk. Od 1919 r. w służbie dyplomatycznej RP. Zwolniony po przewrocie majowym. 3 X 1939 - 7 XII 1939 minister bez teki w rządzie Sikorskiego z ramienia Stronnictwa Ludowego. W latach 1940-1945 poseł w Bernie w randze chargé d'affaires ad interim. Roztoczył opiekę nad internowanymi żołnierzami polskimi i kierował tzw. grupa berneńska, która w latach 1941-1943 wystawiała nielegalne paszporty latynoamerykańskie Żydom z gett w okupowanej Polsce.

${ }^{54}$ Władysław Raczkiewicz (1885-1947), polski polityk i prezydent. Minister spraw wewnętrznych w 1921 r. oraz w latach 1925-1926 i 1936. Marszałek senatu w latach 1930-1935. Po internowaniu władz polskich w Rumunii obją stanowisko prezydenta RP 30 IX $1939 \mathrm{r}$. i sprawował je do 1945, a jako prezydent RP na uchodźstwie do 1947 r. 

E. l'Egypte (selon Havas)
F. le Brésil (selon Reuter)

\section{Position des Etats neutres}

Ont accusé récepion de la notificaion faite par la Légation de Pologne du changement de Président:
A. le Danemark,
B. la Suède
C. la Suisse.

La question est à l'étude en:
A. Finlande,
B. Norvège,
C. Pays-Bas.

\section{$2^{\circ}$}

Le 18 septembre dernier, le Gouvernement polonais fait savoir au Corps diplomatique que celui-ci continue automatiquement à être accrédité auprès du Gouvernement à transférer dans une ville française. D'autre part M. Szuyski ${ }^{55}$, chargé d'affaires de Pologne à Bruxelles, a fait, de 6 octobre, une démarche officieuse auprès du Service du Protocole, pour signaler que son Gouvernement ne s'attendait pas, dans les circonstances actuelles, à recevoir des lettres de re-créance pour les diplomates accrédités jusqu'à présent auprès de M. Moscicki. Ceux qui étaient en fonctions seront considérés comme régulièrement accrédités auprès de son successeur.

\section{Attitude des différents pays neutres à cet égard.}

Danemark, Norvège, Suède maintiennent actullement dans leurs pays respectifs les Ministres qu'ils avaient accrédités à Varsovie. Le Ministre de Danmark ${ }^{56}$ est officielement en congé et sera «absent» pendant deux mois environ.

Pays-Bas: la question ne sera examinée que lorsqu'une solution aura été donnée à la question du principe de la reconnaissance.

Finlande et Suisse adoptent une attitude d'attente.

D'autre part les Pays-Bas et la Suède ont décidés de renvoyer à Varsovie un Secrétaire de Légation afin de sauvegarder leurs intérêts.

\section{C) Position juridique de la question de la reconnaissance:}

Les éléments constitutifs de l'Etat sont une population régie par les lois particulières, un territoire délimité et un Gouvernement indépendant.

\footnotetext{
${ }_{55}$ Nie znaleziono informacji na temat tej osoby.

${ }^{56}$ Peter Christian Schou (1883-1967), dyplomata duński. W latach 1934-1939 był posłem pełnomocnym Królestwa Danii w Warszawie.
} 
Incontestablement, ces éléments ne se trouvent plus réunis en ce qui concerne la Pologne. Cependant, prendre dès maintenant une attitude négative à l'égard de la reconnaissance de l'Etat polonais serait reconnaître un caractère définitif à la disparition des ces éléments.

Or, aussi longtemps que dure la guerre, on ne peut dire que la situation créée par les armes doit être considérée comme durable. Notre attitude de neutralité nous interdit de nous prononcer prématurement à cet égard.

Dès lors, nous pourrions comme le Danemark, la Norvège et la Suède, maintenir provisoirement à Bruxelles M. Peternotte de la Vaillée que le Gouvernement polonais considère comme accrédité auprès de lui sans qu'il soit besoin de lettres de re-créance.

Entre temps, le Gouvernement belge pourrait, lors d'une prochaine réunion des représentants au Groupe d'Oslo, s'efforcer d'arriver à une solution commune. Mais il devrait tenir compte d'un fait important: les Pays-Bas, le Danemark, la Finlande, la Norvège et la Suède n'ont que des intérêts minimes en Pologne; alors que la Belgique y a investi environ $1 \frac{1}{2}$ milliard et vient, au point de vue de l'importance des investissements, au $3^{\mathrm{e}}$ rang après la France et les Etats-Unis d'Amérique.

/Brak podpisu/.

\section{4}

Légation de Belgique, Varsovie, le $1^{\text {er }}$ décembre 1939.

$7907 / 2889 / 965^{57}$

[A.] Hupperts, vice-consul de Belgique, à Monsieur P.-H. Spaak ministre des Affaires Etrangères et du Commerce Extérieur

Objet: Occupation allemande en Pologne

\section{Occupation allemande en Pologne}

Après plusieurs semaines de tâtonnement, l'occupation par l'Allemagne des territoires polonais prend une forme plus précise.

Le Gouvernement Général sous la direction du Dr. Frank a établi son siège à Cracovie, abandonnant Varsovie qui administrativement dépend de Cracovie. Je signale en passant que cette mesure place les agents de pays étrangers dans une situation difficile pour l'obtention des renseignements étant donné que toute question importante est examinée à Cracovie.

Je crois utile de vous décrire dès à présent le caractère de l'occupation allemande tel qu'il résulte des témoignages qui m’ont été rapportés et de mes observations personnelles.

En premier lieu une différence de traitement de la population existe entre les territoires incorporés au Reich et ceux du Gouvernement Général.

${ }^{57}$ AMAEB, t. 11 058, Oryginał. Na marginesie: «4 exemplaires». 
Pour les premiers, et suivant les récits des refugiés de Posnanie, la volonté d'anéantir l'élément polonais est flagrante. Je n'ai retenu que les témoignages d'anciens administrateurs belges, ou d'autres personnes connues précédemment à la Légation. Tout en faisant la part des exagérations fatales provenant de l'absence de communications normales, la personalité des témoins, les noms cités par eux, les pertes subies dans leur famille même, donnent à leurs déclaration un sérieux suffisant pour être consignées ici.

Ces exécutions auraient été effectuées sur les places de villages ou de villes, les victimes étant prises au hazard dans la foule.

Des familles entières comprenant vieillards, femmes et enfants aeraient parquées dans les bâtiments militaires désaffectés et dépourvus d'eau, de feu et de la lumière. Dans ces espèces de camps la mortalité est très élevée.

Un de mes interlocuteurs qui a pu visiter sa famille internée près de Poznan, m'a affirmé que deux enfants de quelques mois - ses neveux y depérissaient. L'officier qui l'accompagnait était honteux du spectacle présenté par ces malhereux et a accusé le Gestapo de procédés aussi barbares qu'il qualifiait de «Kulturschande» ${ }^{58}$. Il aurait même ajouté que l'armée allemande était révoltée de ces cruautés et qu'un réglement de comptes aurait lieu entre la Reichswehr et la Gestapo.

Les grandes propriétés terriennes sont morcelées et confisquées. Les propriétaires quand ils échappent au massacre, sont parfois autorisés à administrer une partie de leurs biens contre retribution de 10 zlotys par jour.

Des déportations massives de population ont été faites à Gdynia notamment afin de permettre aux Baltes allemands de s'y installer. Les habitants polonais de Gdynia auraient eu quelques heures pour préparer leurs valises. Leurs maisons qu'ils devaient laisser en parfait état ont été immédiatement occupées par les nouveaux venus de Lettonie et d'Estonie.

Les entreprises industrielles sont mises sous contrôle alemand; tout le personnel technique polonais serait licencié. La population a été invité à se faire inscrire au rôle de chomage. Ceux qui se sont soumis à cette formalité seraient envoyés en Allemagne dans les usines manquant de main-d'oeuvre. Les autres se trouvent dans l'impossibilité absolue de gagner leur vie.

Il apparaît que pour ces territoires rattachés au Reich la politique pratiquée se resume en ces mots «Die Polen ausrotten» ${ }^{59}$.

Les entreprises étrangères elles-mêmes ne sont pas épargnées, ainsi qu'il résulte des renseignements que je vous ai communiqués au sujet des usines Cegielski (voir ma lettre $\mathrm{n}^{\circ} 2876$ du 27 novembre $1939^{60}$ ).

\footnotetext{
${ }^{58}$ Niem. „Hańba cywilizacji”.

${ }_{59}$ Niem. „unicestwić Polaków”.

${ }^{60}$ Nie znaleziono w zbiorach AMAEB.
} 
A Lodsch [Łódź] par exemple d'après plusieurs temoins, la sitation est aussi affreuse pour tout ce qui est polonais ou juif. Confiscations d'appartements, expulsions en pleine nuit, intimidations et vexations de toutes sortes se succèdent, plongeant la population dans une terreur sans cesse renouvelée. Ceux qui ont pu gagner Varsovie refusent de retourner à Lodsch y abandonnant tous leurs biens. Tous les appareils de radio ont été confisqués. La presse est, évidemment rédigée par les autorités, si bien que les nouvelles les plus folles circulent dans la population terrifiée.

Dans le territoire dit du «Gouvernement Général» le régime est jusqu'à présent moins révoltant que dans l'autre partie. Cependant il présente un tableau aussi lamentable.

Un des premiers actes du Gouvernement Général a été de décréter la confiscation de tous les biens appartenant à l'Etat polonais.

Dans une ordonance parue le 22 novembre, les «besoins de la communauté» ont été invoqués pour justifier cette mesure.

De deux sources dignes de foi, j'ai appris que le corps professoral de l'Université de Cracovie avait été arrêté pendant une séance plénière et déporté à Breslau sous pretexte que la réunion s'était tenue sans autorisation du Gouvernement Général. Ici également tous les postes de radio et toutes les voitures ont été confisqueés ou requisitionnés. J'ai eu personnellement l'occasion de voir des parcs de voitures saisies et réservés aux autorités administraives. Les peines les plus sévères sanctionnent les tentatives de se soustraire aux réquisitions.

Dans le quartier occupé par la Gestapo, à Varsovie, les coups de feu sont fréquents au milieu de la nuit. Le couvre-feu étant imposé à partir de $8 \mathrm{~h}$. du soir, toute personne se trouvant dans la rue après cette heure sans autoristaion risque l'emprisonnement, et de diverses sources il m'a été dit que les fusils ou les revolvers partaient trop vite sans laisser le temps aux malhereux d'expliquer leur présence.

Les expulsions et dépossessions d'appartemens rivés sont fréquentes. Dans le voisinage immédiat de la Légation, des Polonais que nous connaissons ont été forcés de quitter dans les 20 minutes leur appartement qui a été occupé par les Allemands immédaitement après. Tous les meubles et objets ont du être abandonnés et d'après les chargements effectués le soir dans les camions automobilles, l'occupant emporte sans scrupule la propriété privée des citoyens dont la seule faute est d'être Polonais.

Le directeur de la S[ocié]té Belge des Tramways suburbains de Varsovie, israélite d'origine, a été emmené entre deux soldats rejoindre plusieurs de ses correligionnaires convoqués par la Gestapo. Seule sa qualité de consul honoraire de la République Dominicaine lui a épargné des confiscations et vexations de toute espèce. A Cracovie, les Juifs ont été forcés de porter un brassard blanc portant étoile hébraïque afin d'être plus facilement reconnaissables. Pour Varsovie, la création d'un ghetto entièrement fermé et d'où les Juifs ne pourraient sortir est envisagée. 
La délation commence à faire ses ravages et la difficulté de s'assurer la collaboration de la police allemande, permet aux gens sans scrupules de se saisir des biens de propriétaires absents.

La coordiantion des trois pouvoirs occupants; militaire, civil, policier (Gestapo) n'existe pas et d'après mon expérience personnelle, ils semblent plutôt se contrarier mutuellement.

L'approvisionnement de la ville est plus facile qu'au mois d'octobre, mais les prix pour les produits de première nécessité ont quintuplé. Le problème des transports de personnes et de marchandises est de plus en plus aigu et les arrivages de charbon et d'essence sont insuffisants.

D'après un temoin sérieux, les campagnes entourant Varsovie dans un rayon de $100 \mathrm{~km}$ seraient, au Nord et Nord-Ouest complètement vidées de leurs approvisionnement en farine, viande, bétail, pommes de terre. On estime généralement qu'il ne sera pas possible d'assurer jusqu'à la moisson prochaine l'approvisionnement de l'ancienne capitale polonaise. Des cartes de rationnement seraient incessement introduites pour sauvegarder quelques stocks de denrées indispensables.

L'activité économique à Varsovie et dans le reste du territoire est presque entièrement arrêtée. Le nombre de chômeurs atteint les chiffres maxima. L'incapacité pour la populattion de trouver un gagne-pain crée une situation tragique. Chacun vit actuellement sur ses économies et se demande avec angoisse ce que l'avenir apportera.

Il en résulte que les demandes de visas pour l'étranger se multiplient. Les autorités allemandes accordent assez facilement le visa de transit, si le visa de destination vers un pays neutre est octroyé. Etant donné la classe sociale à laquelle appartiennent les premiers partants, certains veulent y voir l'intention allemande de détruire toute élite intellectuelle capable de maintenir contre l'occupant la résistance morale de la population.

La ferméture des écoles et des Universités, le pillage et la confiscation des patrimoines artistiques et scientifiques dans les musées et laboratoires confirment cette volonté de faire des "territoires de l'Est» un état paysan au service de l'Alleamgne. La Pologne doit devenir, dans l'esprit de l'occupant, le «Bauerstaat» tout juste digne de fournir au «Herrenvolk» une partie des approvisionnements dont il a besoin.

Le sentiment d'insécurité dans lequel vit la population ne fait qu'augmenter et les polonais du Gouvernement Général, s'attendent à subir le même sort que leurs compatriotes des territoires annexés au Reich. Cette tragique situation explique, sans cependant le justifier entièrement, le désir des élites intellectuelles et sociales de quitter la Pologne. Abandonnée en septembre par ses chefs politiques et militaires, et maintenant par les éléments qui pourraient conserver et maintenir devant l'occupant l'idée nationale, la population offrira une moindre résistance à l'emprise allemande. En outre la misère terrible qui ne fera qu'augmenter pendant ces mois d'hiver, prépare la masse qui n'a rien à perdre à accepter l'idéologie communiste. Les nouvelles des 
confins de l'Est assurent l'opinion que l'occupation soviétique est moins dure que l'allemande pour le peuple. En outre la minorité israélite est convaincue de pouvoir jouer un rôle de premier plan sous le régime des Soviets.

Il en résulte que certains éléments souhaitent et appellent une occupation soviétique. Les faits rapportés ci-dessous montrent la détresse et le désarroi dans lesquels est plongée la population polonaise. Elle doit être aidé moralement et matériellement.

Dans l'ordre d'urgence, un secours en vivres et surtout en aliments condensés pour enfants est nécessaire. Les comités de secours américains et de la Croix-Rouge Internationale de Genève ont été approchés à ce sujet.

Mon témoignage sera peut-être utile pour convaincre les personnalités belges, disposant de quelque influence auprès des organismes précités, d'agir de toutes leurs forces afin d'accélerer l'envoi des secours indispensables.

Par ailleurs, plusieurs personnalités polonaises m'ont demandé si notre pays ne pourrait accepter un nombre restreint et choisi de jeunes gens polonais en âge d'Université, que l'occupation arrête en plein développement intellectuel. En permettant à un noyau de jeunes gens poursuivre leur formation, mes interlocuteurs veulent assurer à la nation la conservation de l'élite intellectuelle dont on veut la dépouiller.

Je n'ignore pas que nos Universiés et Ecoles supérieures sont fréquentées par un nombre déjà considérable d'étudiants de nationalité polonaise; la grande majorité d'entre eux est d'origine israélite et d'après l'expérience de ces dernières années, plutôt désireux de s'établir chez nous que de rentrer en Pologne. La demande qui m'a été adressée ne porte pas sur cette catégorie et les jeunes gens qui seraient admis à étudier en Belgique comprendraient plutôt les fils de vieilles familles polonaises vraiment représentatives de la nation.

J'estime de mon devoir de transmettre ce voeu qui pourrait recevoir un commencement de réalisation pratique par la délivrence d'un nombre climitéc de visa.

A. Hupperts

A. Paternotte de la Vaillée, ministre de Belgique en Pologne, à Monsieur P.-H. Spaak, ministre des Affaires Etrangères et du Commerce Extérieur. Note pour le Secrétariat Général

Bruxelles, le 21 février $1940^{61}$

${ }^{61}$ AMAEB, t. 11 058, Rękopis. 
Le rapport ci-joint du Vicomte du $\mathrm{Pau}^{62}$ (9 février $\mathrm{n}^{\circ}$ 323/144) a fait l'objet d'un entretien que j'ai eu en janvier avec M. Litwinski ${ }^{63}$.

Je lui ai signalé les inconveniants que ressultéraient avant tout pour les Polonais si notre représentation de fait à Varsovie était soumise à des mesures malveillantes de la part des occupants.

Il a été convenu, en conséquence, que le chargé d'affaires de Pologne prévient son gouvernement de donner les conseils de prudence aux services de propagande française et recommanderait notamment à ceux-ci d'éviter de citer, à tort ou à raison, des fonctionnaires belges. Une lettre a déjà été envyée à Angers dans ce sens. Une demande verbale suivra.

Paternotte de la Vaillée

16

Bruxelles, le 7 mars 1940

29, Avenue des Gaulois. Tel. 33-22-47

Légation de la République de Pologne à Bruxelles

$\mathrm{Nr} 413 / \mathrm{B} / 8^{64}$

A Son Excellence

Monsieur Paul-Henri Spaak

Ministre des Affaires Etrangères et du Commerce Extérieur à Bruxelles Monsieur le Ministre,

D'ordre de mon gouvernement, j'ai l'honneur de communiquer à Votre Excellence ce qui suit:

Les autorités allemandes d'occupation en Pologne procèdent actuellement à la confiscation générale des objets appartenant à l'Etat polonais ou aux ressortissants polonais et ayant une valeur historique ou artistique ${ }^{65}$ (tableaux, livres, et manuscrits, argenteries, porcelaines, tapis, etc.). Cette mesure constitue une violation flagrante de l'art. 46 al. 2. de l'annexe à la IV-e Convention de la Haye sur les lois et coutumes de la guerre sur terre, dont la teneur est la suivante: «La propriété privée ne peut pas être confisquée», ainsi que de l'art. 56 de l'annexe à la dite Convention ainsi conçu: "Les biens des communes, ceux des établissements consacrés aux cultes, à la charité et à l'instruction, aux arts et aux sciences, même appartenant à l'Etat, seront traités comme la propriété privée. Toute saisie,

\footnotetext{
${ }^{62}$ Brak danych.

${ }^{63}$ Leon Litwiński (1887-1969) został chargé d’affaires Ambasady RP w Brukseli (1 XI 1939

- V 1940). Pełnił tę funkcję równocześnie w Luksemburgu. Przy rządzie belgijskim na emigracji nie został akredytowany.

${ }^{64}$ AMAEB, t. 11 058, Oryginał.

${ }^{65}$ Podkreślone ołówkiem.
} 
destruction ou dégradation intentionnelle de semblables établissements, de monuments historiques, d'oeuvres d'art et de sciences, est interdite et doit être poursuivie».

Le Gouvernement polonais élève une protestation solennelle contre cette nouvelle violation du droit internationale par l'Allemagne qui se rend ainsi coupable d'un pillage sans précédent dans l'histoire des peuples civilisés.

Le gouvernement polonais se réserve le droit d'exiger au moment opportun la réparation complète des dommages infligés ainsi par l'Allemagne à l'Etat et aux ressortissants polonais. Cependant dès à présent il tient à mettre en garde les Gouvernements et les ressortissants des pays tiers contre les tentatives allemandes de vente à l'étranger des objets confisqués illégalement à l'Etat ou aux ressortissants polonais. Le Gouvernement polonais se réserve le droit pour lui et pour ses ressortissants de revendiquer la propriété polonaise qui serait illégalement confisquée par l'Allemagne et vendue ensuite à l'étranger, une vente pareille ne pouvant créer pour les acheteurs aucun droit sur les objets provenant du pillage allemand ${ }^{66}$.

Je prie Votre Excellence de bien vouloir prendre note de ce qui précède ${ }^{67}$ et je saisie cette occasion pour Lui présenter les assurances de ma plus haute considération.

L. Litwiński

Ministre Plénipotentire, chargé d'affaires a.i.

\section{7}

Consul honoraire ${ }^{68}$ de la Belgique en Pologne occupée au Ministre des Affaires Étrangères et du Commerce Extérieur, P.-H. Spaak.

Objet: Le témoignage sur les atrocités allemandes en Pologne.

Bruxelles, le 26 mars 1940.

Monsieur le Ministre,

J'ai l'honneur de joindre à la présente un petit rapport sur le voyge de quatre semaines que je viens de faire en Pologne.

Je vous prie de croire, Monsieur le Ministre, à l'expression de mes sentiments de haute considération.

$\underline{\text { Confidentiel }}^{69}$

Note de mon voyage en Pologne du 6/II au 6/III/40.

\footnotetext{
${ }^{66}$ Podkreślone ołówkiem.

67 Podkreślone ołówkiem.

${ }^{68}$ Nie zdołano ustalić nazwiska tej osoby.

69 AMAEB, t. 11 058, Oryginał.
} 
La question du jour lors de mon arrivée à Varsovie le 10/2 était le retrait de billet de $100 \& 500$ zlotys qui devaient être estampillé par l'occupant.

J'ai eu l'occasion d'un entretien avec M. Mlynarski ${ }^{70}$, ancien délégué à Génève du Gouvernnement polonais, directeur actuel de la Banque d'Emission fondée par l'occupant, qui me donna les explications suivantes. Le but des Allemands était de rendre à la circulation les sommes détenues par les paysans, de se défendre des faux billets mis en circulation par la commission soviétique venue en Pologne pour les échanges de population, de donner certaines liquidités aux banques dépourvues de fonds tout comme d'enrayer le retour des zlotys de l'étranger.

Cette mésure ne donna aucun résultat car si un certain nombre de billets furent estampllés, les quantités furent insuffisantes, les vieux billets continuèrent à circuler parmis les spéculateurs moyenant un agio de 20 à $25 \%$. Bon nombre de billets restent bloqués chez les détenteurs qui craignaient la confiscation pure et simple.

Le professeur Mlynarski me semble regretter la fonction quil accepta croyant être utile à son pays car il est à tout moment mis devant le fait accompli et la presse par exemple publie des interviews qu'il n'a jamais donnés.

Il va de soi que la presse polonaise est sous le contrôle forcé des Allemands et que pas un journaliste polonais sérieux ny collabore.

L'industrie et le commerce ne marchent que pour autant qu'ils aient un rapport directe ou indirecte avec les besoins de l'armée et de l'alimentation.

Les centrales électriques du groupe de l'Electrobel marchent normalement, les hauts fournaux d'Ostrowiec du trust métallurgique belge occupent environ 1.700 ouvriers pour la construction de charpentes métalliques et de wagons de marchandises.

Tout l'industrie textile, vivant uniquement sur les stocks, a encore du travail pour jusque juin-juillet. Les propriétaires israélites ont été en général expropriés, les autres travaillent sous la direction de «Treuhänder» ${ }^{71}$. Dans certains cas les Allemands ont proposé le paiement valeur d'avant guerre, en marks bloqués. Dans la plupart des cas la marchandise est a) dans les

${ }^{70}$ Feliks Młynarski (1884-1972), ekonomista i bankier. W latach 1921-1922 dyrektor Urzędu Emigracyjnego. Przyczynił się do przeprowadzenia w 1924 r. reformy walutowej zainicjowanej przez premiera Władysława Grabskiego. Współtwórca Banku Polskiego SA i jego wiceprezes (1924-1929). W latach 1933-1935 pracował w Komitecie Finansowym Ligi Narodów. W czasie II wojny światowej za zgodą premiera rządu polskiego na uchodźstwie Sikorskiego zgodził się na objęcie stanowiska prezydenta Banku Emisyjnego w Polsce, powołanego przez gubernatora Generalnego Gubernatorstwa Hansa Franka. Od jego nazwiska okupacyjne banknoty były nazywane „młynarkami”.

${ }^{71}$ Niem. „powiernik”. W czasie II wojny światowej tym mianem Niemcy określali administratora poszczególnych zagrabionych przedsiębiorstw oraz majątków zlikwidowanych instytucji. Stanowiska te zajmowali przeważnie Niemcy zamieszkali w Polsce przed wojna. 
contrées annexées au Reich réquisitionnée, b) dans le «Gouvernement» ou «Protectorat» volée.

$\mathrm{Ci}$ joint une carte de division du pays ${ }^{72}$, carte toutefois sujette à caution vu les rectifications continuelles des autorités.

Pour ce qui est du grand négoce à Varsovie, sécialement aux mains d'Israélites, il es tout simpliment dévalisé. Le petit commerce de détail se meurt petit à petit ne pouvant remplacer les stocks et même bon nombre de magasins ont été dévalisés sans indemnité. Les magasins ferment les uns après les autres.

Le vol est presque légalisé et c'est par milliers que l'on eut citer les cas de pillages des appartement privés, par la troupe et plus particulièrement par la gestapo.

Les bureaux fiscaux ont repris toute leur activité au profit de l'occupant naturellement. Les Polonais ont accès aux emplois subalternes seulement.

Il est impossible de parler d'une organisation quelconque le pays étant dirigé par trois organisme: 1) la gestapo, 2) l'administration militaire, 3) l'administration civile. Ces trois organisme semblent n'avoir aucune cohésion et les prescriptions données sont à tout instant modifiées.

Le pillage systématique est le seul point sur lequel cs tris organismes semblent d'accord.

Un faible essai d'autonomie a été fait pour ce qui concerne le «Protectorat» et le prince Radziwill a été consulté à cet effet. Cet essai n'a rien donné, le prince ayant posé comme condition première le retrait immédiat de l'administration civile et de la gestapo.

Je ne puis traduire l'activité de la gestapo que par deux mots: vols \& assassinats et j'ai conviction que tout ce que la presse écrit à ce propos est en dessous de la vérité.

Nombreux sont les gens qui disparaissent et dont on n'entend plus parler. Nombreux sont les malhereux que l'on met dans des camps de concentration! Il ma été donné d'entendre par un témoin, libéré le 20/2, ce que s'y passe et je cite trois cas donnant une idée des traitements que la culture allemande inflige à ces malhereux:

1) Les frères Eisner, grands industriels de Lodz, ont été obligés de ce couper mutuellement la barbe avec un couteau de cuisine, puis de se gifler.

2) M. Henri Barcinski, administrateur de la S.A. S. Barcinski and Co à Lodz, a eu la tête cognée contre le mur jusqu'à ce qu'il perde connaissance, couvert de sang. Il est actuellement mourant à Varsovie.

3) Deux vieux prêtres, agé d'environ 70 ans ont été forcés de faire de genoux-flexions jusqu'à ce qu'ils s'évanuissent. Ils ont été rappelés à la vie à coups de bottes.

\footnotetext{
${ }^{72}$ Nie znaleziono w dossier.
} 
J'ai de mes yeux vu entre autres brutalités à Varsovie les deux scènes suivantes:

1) Un vieillard étant monté par erreur sur la plate-forme de devant du tram, réservée aux boches, fut descendu à coup de pieds.

2) Une Israélite, sur le pont Poniatowski, pour avoir omis de porter son brassard (schandband) s'est vue, par punition, dévaliser de sa fourrure qui fut jetée dans la Vistule. L'énergumène de la gestapo voulait encore l'obliger à se déchausser, par 25 degrés de froid et à rentrer pieds nus. L'intervention de quelques soldats de l'armée regulière mit fin à cette scène.

A Lodz où le ghetto s'organise dans des condditions qu'il est impossible de décrire, les suicides se comptent par centaines.

Pour terminer les exemples de la culture allemande j'en cite un dernier caractéristique. Une quinzaine de jeunes filles de 15 à 20 ans furent arrêtées dans les rues de Varsovie, conduites à la Chambre des Députés où la gestapo fusille presque journellemnt, ces malhereuses furent forcés de se débarasser de leur linge de dessous avec lequel on les força à laver les vitres. Ensuite elles furent obligées de se vêtir et relachées. L'une d'elles, Helle Batley, fille d'un fourreur très connu mourut trois jours après. Il est indiscutable que le but de l'occupant est de détruire tout élément intellectuel du pays.

Les dernières préscriptions officielles sont les suivantes:

a) Obligation de déclarer les antiquités et oeuvres d'art datant d'avant 1850.

b) Obligation à tous les sans travail sans distinction de classe et de sexe de se faire enregistrer.

La population n'a pas répondu à l'enregistrément des oeuvres d'art qui seront certainement volées comme toutes les oeuvres d'art des musées.

Quant à l'enrégistrement de sans travail contre lequel chacun se défend comme il peut, se cherchant une occuatuin fictive, il donnera comme résultat le transport en Allemagne de milliers d'intellectuels, ceux-ci surtout n'ayant pas d'occupation.

La situation au point de vu alimentaire est encore passable pour ceux qui ont de l'argent; mais il est à craindre que dans quelques mois cette situation sera catastrophique!

Dans un but de propagande les autorités locales ont fait imprimer des étiquettes U.R.S.S. qui sont collées sur des marchandises d'origine polonaise expédiées en Allemagne. 